\title{
Mobile Application Tools for Students in Secondary Education. An Evaluation Study.
}

\author{
https://doi.org/10.3991/ijim.v12i2.8158 \\ Zoe Karabatzaki \\ School Advisor at the Ministry of Education, Greece \\ Agathi Stathopoulou \\ Center for Diagnosis, Differentiation and Support, Athens, Greece \\ Georgia Kokkalia, Eleni Dimitriou, Paraskevi Ioanna Loukeri \\ National Center for Scientific Research "Demokritos", Agia Paraskevi, Attica, Greece \\ Alexandra Economou \\ University of Athens, Athens, Greece \\ Athanasios Drigas $(\stackrel{\square}{(-)}$ \\ National Center for Scientific Research "Demokritos", Agia Paraskevi, Attica, Greece \\ dr@iit.demokritos.gr
}

\begin{abstract}
Technology has the potential to improve many aspects of our daily lives, including learning. It has been proven to increase student engagement and learning outcomes. With recent advances in the capabilities of smart mobile devices and their growing penetration rate among the student cohort, it is possible to take advantage of these devices to design appropriate exercises and tools that foster student's knowledge and learning. In this paper we present some of the most well known mobile procedures that are used for secondary students in order to promote their learning and their skills. Additionally, its role in secondary students who face learning and other difficulties is investigated. Lastly, the results of a study that examined whether there is a relationship between the performance of secondary school Greek students in the language lesson, in mathematics lesson and index of verbal intelligence, index of intelligence practice and general index of intelligence are showed thoroughly.
\end{abstract}

Keywords—-mobile technology, secondary education, high order thinking skills, special education

\section{Introduction}

The advent of mobile learning technologies into teaching and learning has brought both new possibilities and challenges to teachers and students. Mobile learning represents a technology that is ubiquitous in nature, wireless, highly portable and endowed with multimedia capabilities bringing a new dimension to curriculum delivery [1].The 
last few years have witnessed an impressive increase in the use of mobile learning technologies in schools, although created for a non-educational environment, soon made their way into the classroom. These devices have attracted interest from the educational community mainly due to their versatile gaming capabilities [2]. Each new version of these devices brings innovative features that make them more convenient and affordable, and new apps continually become available that make our lives easier. These advances have prompted educators and researchers to utilize these devices to promote teaching and learning. There is great potential in using mobile devices to transform how we learn by changing the traditional class- room to one that is more interactive and engaging. It allows educators to teach without being restricted by time and place, enabling learning to continue after class is over or outside the classroom in places where learning occurs naturally). It also gives educators the ability to connect with learners on a more personal level with devices that they use on a regular basis, while sensing technologies enable learning to be personalized and customized to the individual learner [3].

Moreover, mobile learning allows students to engage in problem solving based learning activities and to work on tasks that are goal oriented and open-ended with a strong gaming component [4]. In addition, mobile learning devices empower students to develop their own understanding through active involvement and sense making thus learning experiences like digital simulations or manipulations have the capacity to bring interactivity enhancing cognitive and affective processes[5]. Also, one of the great advantages of mobile devices is that students learn to learn in new contexts such as visiting "virtual" museums or galleries or within different cultural and social settings offering opportunities for collaborative learning in order to share their work through online media [5].

The growing use of mobile technology on college campuses suggests the future of the classroom, including learning activities, research, and even student faculty communications, will rely heavily on mobile technology. The literature suggests that mobile learners desire the ability and flexibility to choose their location and time for learning. Greater access to personal mobile tablets might allow learners greater opportunities to collaborate with others and construct knowledge in real world experiences in their daily lives. Some smaller, private institutions have provided iPads or other mobile devices to incoming students in the past two years [6].

On the other hand, for students with special education needs who exhibit difficulties in learning due to cognitive, physical and sensorial disabilities, one of the main objectives in the classroom is to improve their behavior and their relationships with their environment. But at the same time these students must learn to perform daily activities autonomously, improve their communication, develop cognitive abilities and acquire new knowledge. To do this, alternative communication systems based on interaction with pictograms or pictures are typically used [7]. Activities that are used in special education are the same as those used in early elementary school level, or a variation of them. Adaptation of learning activities is necessary in this context because the students often have many different syndromes and pathologies (autism, Asperger's syndrome, Down syndrome, etc.), and varying abilities and skills. Their 
work rhythm and learning needs are also different and thus, individualization in the learning process is necessary[ 7].

As a result, is essential to help students with special education needs to achieve greater autonomy so that they can independently perform day-to- day activities [8].Technical aids and software adaptations enable them to move, travel, undertake activities, have fun and learn without having to depend on other people. This is all more so the case in an educational environment, where activities should encourage students to develop skills and acquire knowledge that will be useful during their entire life. In this fact, the development of customizable and adaptable applications tailored to users with special education needs brings many benefits as it helps mold the learning process to different cognitive, sensorial or mobility impairments. Therefore, the design of this kind of applications that offer usability (designing easy-to-use applications, ensuring that users can interact with them and understanding both the tasks to be accomplished, and also the response of the system), flexibility (allowing educators to customize and adapt application contents according to both user and educational contexts) and mobility (mobile devices have become a very useful support in constructing learning applications because they provide freedom of movement between different locations within the school) may be really useful for students with learning and educational difficulties [8].

In the light of the above arguments, in this short article we will try to present some of the most important and notable mobile procedures of the last decade in secondary students, that assess the literature and math skills.Additionally, mobile procedures that may intervene to secondary students who face mental or other special difficulties are going to be discussed. Lastly, the results of our research in secondary Greek students that investigate the relationship between their performance in language lesson and performance in mathematics lesson with index of verbal intelligence, index of intelligence practice and general index of intelligence are going to be presented.

\section{Mobile Applications for Assessing Math and Literature Skills in Secondary Students}

The emerging and widespread use of technology to support students in secondary education is evident by the growing number of studies investigating the use of technology-based interventions [9] including mobile technologies [9]. Much of the most recent research on the use of such technology has focused on assessing the learning and cognitive skills of students in order to have a successful and promising academic and personal life. As technology begins to permeate educational programming, school psychology trainers and practitioners alike need to identify the most promising and helpful tools that can be deployed readily within classroom contexts to assist in supporting the education of students. Part of that process not only involves awareness of available technologies, but also awareness and understanding of the extant research literature that supports their use. In a review of the literature in mobile learning, a number of researchers have recognized that games can be motivator for students to learn; hence game-based learning has a great potential. The use of fun is found to be a 
stimulating motivator for students of all ages [10], as games are very popular with every age group. Game-based learning has been used for many different disciplines of education with varying degrees of success. With the increasing use of mobile phones and other similar devices, mobile games, including mobile learning games, are also becoming popular. The advantage of the mobile learning games is that the players can play whenever they wish. Therefore when a player has free time he/she can make optimal use of that time. The results of a survey comparing the usage of mobile games to other digital games indicated that $54 \%$ students preferred playing mobile games [11], on the bus, train, or in a lecture room waiting for the lecture to begin.

Taking the above into consideration, many researchers have also focused on using mobile learning for assessing mathematics in secondary students. Firstly, K-Nect project, targets secondary at-risk students to focus on increasing their mathematics skills through mobile smartphones. Also, another study investigated the effects of solving mathematics problem by 50 -second graders on Game Boy screen before it faded away. Results indicated that students who played more performed better. Furthermore, the application, MobileMath, offers several methods to help students learn mathematical skills. Learners learn through learning by doing by practicing their skills in the games. The learners therefore engage in direct experience and focus on learning reflection to increase their knowledge, skills, and values. MobileMath uses various personalization rules for creating the recommendations for the learners, assisting them in choosing activities and easing the navigation. Also, consists of several features such as games, lessons, tutorials, examples and quizzes, which offer a different strategy for learning the topic. The algebra content is embedded into the game itself in a way that an algebraic skill is required for playing each game while there are games for finding factors, adding and subtracting directed numbers, factorization and solving equations. In addition, Construct3D is a three-dimensional geometric construction tool specifically designed for mathematics and geometry education. It is based on the mobile collaborative augmented reality system "Studierstube" and according to studies improves spatial abilities and maximizes the transfer of learning. Together with hybrid hardware setups this tool allows the use of Construct3D in today's classrooms and provides a test bed for future evaluations. According to evidence studies, Construct 3D is easy to learn encourages experimentation with geometric constructions and improves spatial skills [12].

On the other hand, there is the general opinion that iPad applications are being used as an additional tool for learning within educational environments improving the academic skills of children. A recent pilot study investigated the efficacy of iPad applications in improving the literacy and overall academic skills in children. Results suggested that while statistical significance was not obtained, practical significance was found for the use of iPad applications to support learning in the literacy skill area of spelling knowledge and number concept. Also, the iPad applications that were chosen for this project were selected with several key criteria in mind and mainly focused on the key academic concepts. Besides, they were developmentally appropriate for children with several levels of difficulty through which children could move independently, according to their needs and they provided positive or neutral feedback to children's responses. For the intervention condition, the applications gave 
multiple opportunities for the child to learn about and practice at least one of the skill areas [13]. Furthermore,the advancement of mobile and wireless communication technologies has encouraged an increasing number of studies concerning mobile learning, in which students are able to learn via mobile devices without being limited by space and time; in particular, the students can be situated in a real-world scenario associated with the learning content. Although such an approach seems interesting to the students, researchers have emphasized the need for well-designed learning support in order to improve the students' learning achievements. Therefore, it has become an important issue to develop methodologies or tools to assist the students to learn in a mobile learning environment. Based on this perspective, a current study proposes a formative assessment-based approach for improving the learning achievements of students in a mobile learning environment encouraging also their literacy skills. A mobile learning environment was developed based on this approach, and an experiment on a local culture course was conducted in Taiwan to evaluate its effectiveness. The experimental results show that the proposed approach not only promotes the students' learning interest and attitude, but also improves their learning achievement [14]. Also, the effects of a mobile city game called Frequency 1550, which was developed by The Waag Society to help pupils in their first year of secondary education play- fully acquire historical knowledge of medieval Amsterdam, were investigated in terms of pupil engagement in the game, historical knowledge, linguistic development, motivation for History in general and the topic of the Middle Ages in particular. The results showed that those pupils who played the game to be engaged and to gain significantly more knowledge and linguistic skills about medieval Amsterdam than those pupils who received regular project- based instruction [15].

So from the above short presentation, it is obvious that the involvement of mobile applications in educational system may offer significant results in student's academic and learning performance.

\section{Mobile Learning Applications to Promote Higher-Order Thinking Skills}

According to some recent studies [16] most students in post- industrial countries live with mobile devices and use them extensively. Thus, more and more educationrelated mobile apps have been developed to promote students' overall learning. On the other hand, some scholars [17] believe that higher-order thinking, which facilitates students' knowledge development, is an important concept in education. Thus, it is important to develop these mobile apps and carefully utilize them with collaborative learning theories to support higher-order thinking, and eventually to achieve collaborative learning [18]. The benefits of collaborative learning include learning concepts more effectively, encouraging more participation, improving learning satisfaction, developing teamwork skills, and promoting higher-order thinking. However, it is difficult to apply collaborative learning because students tend to engage passively with traditional lectures [18]. 
On the other hand, students seem to learn better or solve problems correctly when they collaborate with others, especially when the task is conceptual or complex. Furthermore, collaboration among students also seems to have beneficial effects such as improving social relations or increasing motivation thus there is a range of mobile collaborative learning applications available to promote higher-order thinking skills [19]. These include discussion boards, blogs (, and outdoor educational scenarios and games [20]. Discussion boards provide a medium through which learners can collaborate with each other and construct knowledge online. Blogs allow learners to develop and publish a piece of writing, which other learners can then comment upon. Having all the above into consideration, one way to achieve higher-order thinking is to provide learners with a complex problem, such as a case study, to solve, and use discussion boards and blogs as shared online collaborative spaces for interaction. Furthermore, allowing multiple channel access to these interactions (desktops, laptops, smartphones, ) enhances the environment for learners as they can interact with each other under different circumstances [21].

Moreover, a research team [22] supports the view that students can utilize such features to reach consensus in after-class discussions/questions, and promote higherorder thinking even when they are outside of class. Therefore, a research team designed the Smartphone-Supported Collaborative Learning System (SSCLS), which includes the My Response mobile app and the Delphi method. The main purpose of this study was to present the design of a system named Smartphone-Supported Collaborative Learning System (SSCLS) that includes both a mobile app (My Response) and the Delphi method. The contribution of this project includes applying mobile technologies (mobile phones, mobile apps, and servers) in the classroom that offer a user-friendly environment that encourages greater in-class participation. The findings of this study underlie that SSCLS not only addresses the limitations of mobile technologies, but also achieves collaborative learning enhancing better performance in thinking skills [23].

In conclusion, the wide availability of smartphones that can record data and send and receive it, allows savvy and ambitious job applicants to construct digital CVs with foot-age of their behavior in work contexts. That has left some potential employers wondering why they should to the trouble and expense of using psychometric tests to access potential when such direct evidence is increasingly available to them. Recent study attempted to examine how trends in consumer technology, the heightening of interest in the value of psychology and the willingness of consumers to forgo privacy will shape the psychometric testing industry, and perhaps transform it, within a decade. A free smartphone app was experimented to measure personality and to make professional personality testing available to consumers. The app was called 'practical personality test' and the website to which it was linked was called PersonaBubble. The experiment with the practical personality test app and the associated PersonaBubble website had demonstrated how a smartphone-based platform had targeted at consumers could recruit large samples. Disruptions to the current theory and practice of psychometric testing will come from many different directions over the next decade and they will occur at varying speeds. The fastest will be the digital 
badging movement and the most fundamental will be advances in the neuroscience of personality [24].

\section{$4 \quad$ Mobile Applications for Students with Special Needs}

The learning process is supported by an interacting set of elements that characterizes a particular student. The most important of these elements involve the knowledge the students have, their psychological traits and the social environment in which they are immersed. Identifying these elements in order to analyze how these may affect the results in the learning process, allows to decrease their weaknesses and increase their strengths [25]. In this connection, there have been a number of research studies published in the literature, which attempt to explain features and related factors for low performance of students. They identify elements that intervene with educational goals namely: teaching/learning strategy (system causal factor), parents (family causal factors), teachers (academic causal factor), and students (personal causal factor). However, it is obviously impossible to know everything about a student. Therefore, it becomes necessary to choose the most relevant and useful information about him that may influence school performance [26]. Undoubtedly, one of the most important and affecting in school performance factor is student `s intelligence I.Q.

Taking the above under consideration, there are several studies that involve the use of mobile applications to investigate a wide variety of attributes in classroom, ranging from medicine to research applications. An application is essentially a small computer program that can be quickly downloaded onto a mobile computing device, (such as a tablet or smartphone) and immediately engaged without rebooting the device [27]. A relevant study tried to examine the effects of using an augmented reality app, Red Laser, to teach individuals with intellectual disabilities to identify potential food allergens. When participants were provided with an iPad or iPhone equipped with the Red Laser app, participants successfully identified potential food allergens associated with real food items [28]. In addition, mobile apps have been increasingly used to support children with autism. These advanced technologies devices with their associated features provide a comfortable and affordable solution for autistic children and their families. The portability, flexibility, availability, and readiness of features have opened up new opportunities for enhancing and elevating the quality of support to mitigate autistic children deficiencies. Autistic children are known for their impairment in understanding and interpreting the emotional facial expression in others. This impairment has led to difficulties in social interaction skills that have a critical impact on the lives of autistic people, their parents, therapists and healthcare professionals. Research has demonstrated the usefulness of $3 \mathrm{D}$ animation in mobile devices. The animations had been built to the needs of children with autism. The results showed predictability, simplicity, sameness and systematization concepts had been considered when selecting and constructing scene elements. Facial animations had been implemented with caution to alleviate the major difficulty in understanding and recognizing emotions and facial expressions[29]. Furthermore, another study aimed to develop a mobile application on learning the basic numbers for Down syndrome children and to 
evaluate the user acceptance on the developed mobile application. The study focused on the Down syndrome children with moderate level of IQ who were learning to recognize basic numbers. The method had been used to achieve the objectives was Rapid Application Development (RAD). The mobile application was developed using Eclipse Android Development Tool (ADT). An observation had been conducted to 5 Down syndrome children who had different level of IQ. The finding showed that the mobile application was really suitable for Down syndrome children who have moderate level IQ [30].

There has also been growing interest in the last five years in the use of mobile technology with children with ASD. Mechling and Savidge (2011), [31] in an exploratory study, evaluate the use of a PDA with multiple prompt levels, indicating its potential to increase efficacy in completion of novel tasks and transitioning within and between tasks. Gentry, Wallace, Kvarfordt, and Lynch (2010) [32] used standardized measurement tools to measure the efficacy of PDAs as cognitive aids in a sample of high school students with ASD, indicating positive initial outcomes. Reports are also being published on the use of mobile technology specifically to support social skills development. There has been a parallel interest in the use of mobile technology to support students with cognitive disabilities due to traumatic brain injury, stroke or other disease. The MAPS-Lifeline prototype [33] created a GPS based mobile device system. This allowed caregivers (such as care attendants or social workers) to use a script based system to create guides and prompts which gave support for particular tasks where memory and attention functions may need to be bolstered, such as navigating public transport. Evaluation demonstrated the need for personalization; that is interventions delivered on the mobile device need to be tailored to the specific needs of the individual. Another important finding was that the interplay between caregiver and client in monitoring and adjusting the ongoing use of the interventions was important to ensuring success. Additionally, the HANDS project has explored the use of a smartphone application, which allows teachers to flexibly develop interventions on smartphone devices, which support children with ASD with social skills and life skills functioning. The software developed is innovative in that it has used the principles of Persuasive Technology [34] as the basis for the design process. Implementation of a prototype has taken place at four special schools for children with ASD (in the age range 11-16) located in Denmark, Sweden, Hungary and the UK.

Nevertheless, for students, mobile devices seem to be one of the common channels to look for health and wellness information online. A survey reported that $42 \%$ of cell phone owners who were 18 to 29 years old used their phones to look for healthrelated information, such as specific diseases or medical problems and certain medical treatments or procedures, as well as information about how to lose weight or control weight. In particular, with the increased smartphone ownership among the younger age group of 18-to 24-years-old, mobile applications gained ground as channels for tailored health and wellness information distribution and as tools used to monitor, log, studies on online health information have shown that the use of Web health information systems and mobile applications may increase knowledge on the health topics and lead positive health outcomes and more proactive health behavior [35]. Another research documents student 's aim, in museum internship program for high school 
students, to build an app pertinent to their museum exhibit of choice. The students improved the app based on their interactions with the museum visitors. The created students app could be launched on any smartphone (iPhone, android, or Microsoft). This was critical for keeping the museum visitors' experience satisfactory [36].

Of course, mobile devices play an increasingly important role in medical education as students and schools use more technology during training. Health care students in a variety of ways use mobile devices in order to log their experiences, to access information about medical conditions and drug treatment, to perform calculations, and to make basic notes [37]. Mobile devices have become ubiquitous in educational settings, particularly because they are a "learn anywhere" resource for accessing information or double-checking knowledge. Health care students are increasingly relying on mobile devices as a "pocket brain" for quick, easy access to information they need in order to succeed in their programs and careers [38]. Studies have demonstrated that 85 percent of attending surgeons, fellows, and residents in the Accreditation Council on Graduate Medical Education (ACGME) training programs own a smartphone, and more than 50 percent of them use a variety of apps in clinical practice. Also to influencing clinical practice, mobile apps can have a large impact on the accessibility of journal articles. Books, informational resources such as UpToDate have mobile apps of summarized, easily accessible, and searchable information that is readily available and allows for the immediate answering of questions. More interactive educational apps range from quiz apps, including Surgery Board Weapon for the American Board of Surgery In-Training Examination and board review, to those that actually allow a user to perform simulated surgeries [39]. In addition, many mobile apps for health care students can be used for knowledge assessment, such as case study quizzes or tests to help prepare for board examinations. The ability to access all of these resources has been shown to enhance student learning in the clinical environment and to increase student knowledge scores [37].

\section{$5 \quad$ Methodology of our research}

\subsection{Purpose of our research}

The aim of our study was to investigate the relationship between performance in language lesson and performance in mathematics lesson of Greek secondary school pupils with index of verbal intelligence, index of intelligence practice and general index of intelligence.

\subsection{Main research question}

The main research question that we were concerned about was whether there is a relationship between the performance of secondary school students in the language lesson, in mathematics lesson and index of verbal intelligence, index of intelligence practice and general index of intelligence. 


\subsection{Data Collection}

For the purposes of our research we used the WISC-IV intelligence test. This test gives us three indicators. An index of verbal intelligence, an index of practical intelligence, and the average of these two are the general index of the child's intelligence. In addition, teachers were given a small questionnaire on completing pupils' demographics and their performance in language lessons and mathematics lessons.

\subsection{Participants}

The survey involved 160 pupils aged 12-17 years studying in Secondary General and Vocational Secondary Education Schools in Athens and have assessed by the Center of Assessment and Support due to their learning disabilities. For the same students, we received some information from a corresponding number (160) of educators (120 female-40 male). Of the pupils 101 were boys and 59 were girls. Three (3) pupils were 12 years old, 30 pupils were 13 years old, 28 were 14 years old, 34 were 15 years old, 46 were 16 years old and 19 were 17 years old. About the class they were attending, 24 pupils were in first grade, 27 pupils attending second grade, 23 pupils were studying at the third grade, 39 pupils were studying in the 1st Lyceum, 30 pupils were studying in the 2 st Lyceum and 17 pupils were studying in the 3 st Lyceum. Language and Mathematics evaluation in the Greek education system in secondary education varies between $0-20$ points, with best performance the highest grade.

\subsection{Procedure}

We collected our data from October of 2016 to May of 2017 with 160 participants, who are educators in secondary schools in Athens. Moreover, to each participant was given an Android-based cell phone with an online structured questionnaire developed by us. The sample size of this study was about 160 pupils. The questionnaire contained questions recording school performance in literacy and mathematics, parent profession, and parent education. The pupils who participated had visited Center of Assessment and Support due to learning difficulties. The pupils in a special session completed the WISC-IV test of intelligence.

\subsection{Statistical analysis}

Statistical analysis of the data was carried out with the SPSS 23 statistical package. The frequency of pupils' grade in the language lesson, in the mathematics lesson, index of verbal intelligence, index of intelligence practice and general index of intelligence were calculated. We found the Correlations between all variables using the Pearson r Correlation Coefficient (two tailed). Our results are presented in the form of graphs or text 


\subsection{Results}

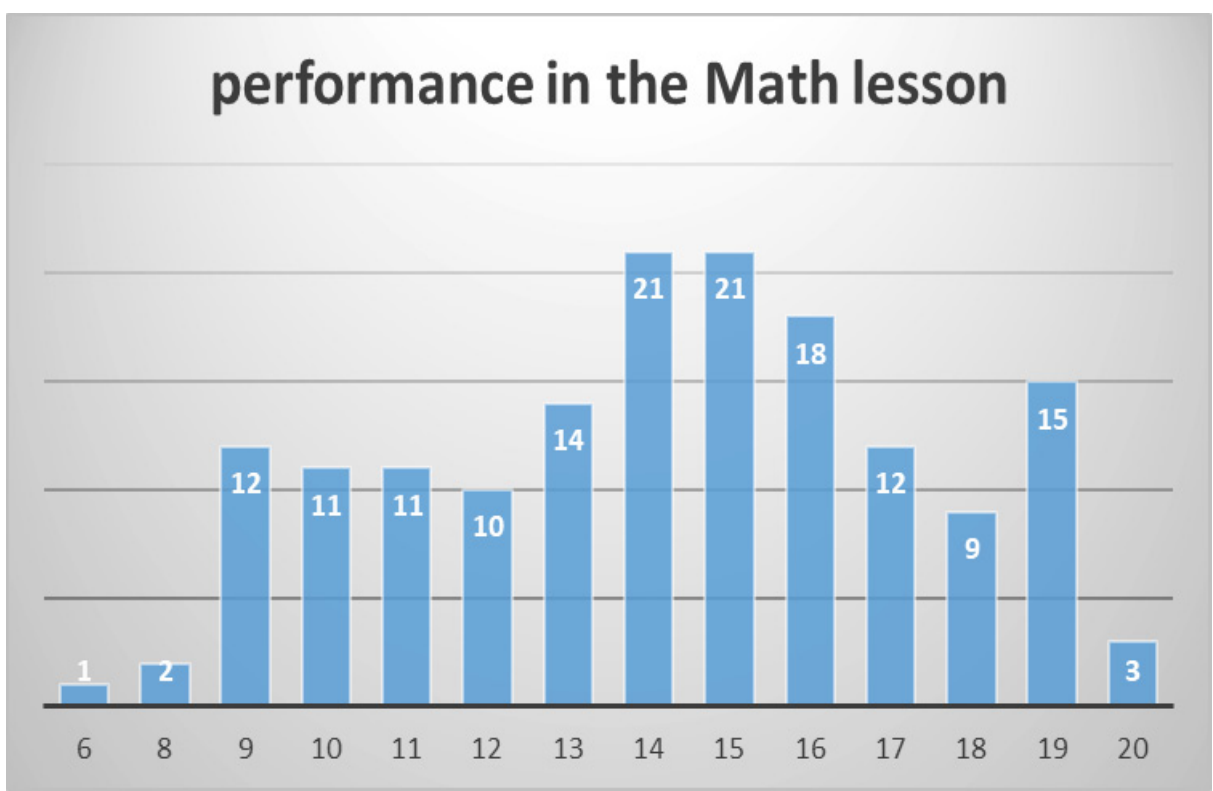

Fig. 1. Graph 1. Frequencies of pupils' performance in the math lesson

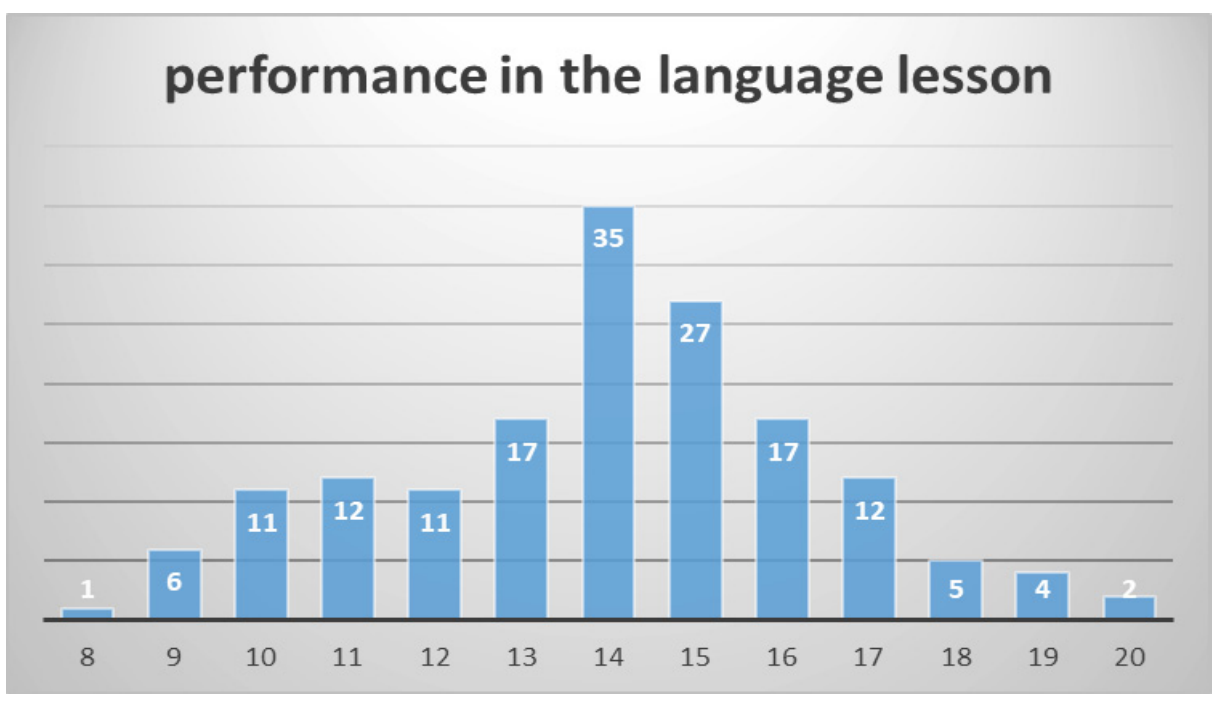

Fig. 2. Graph 2. Frequencies of pupils' performance in the language lesson

In Graph 3, the frequency index of pupils is indexed by verbal intelligence. A large proportion of pupils (76 students) have a verbal intelligence index of 91 to 110 , which corresponds to the average of the general population's verbal intelligence index. A 
fairly large proportion exceeds the average (55 students). A very small part ( 8 pupils) presents a mental disability, 5 pupils appear with marginal intelligence, 13 pupils just below the average and one very small ( 3 pupils) appears to have extraordinary intelligence.

In Graph 4, the indexes of practice intelligence have been described. A large proportion of pupils (77 students) have an IQ of 92 to 110 , which corresponds to the average of the general intelligence practice index. One place exceeds the average (28 students). A small part (23 students) presents a mental disability, 8 pupils appear with marginal intelligence, 22 pupils a little below the average, and a very small part (2 pupils) appears to have extraordinary intelligence.

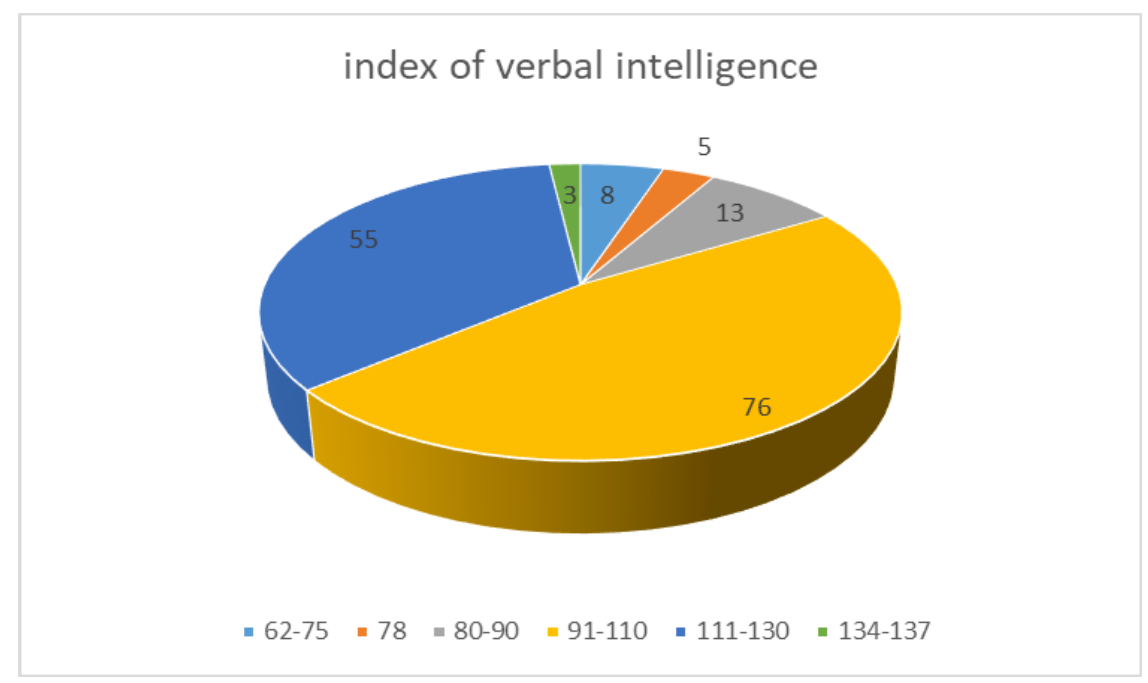

Fig. 3. Graph.3 Frequencies of pupils index of verbal intelligence

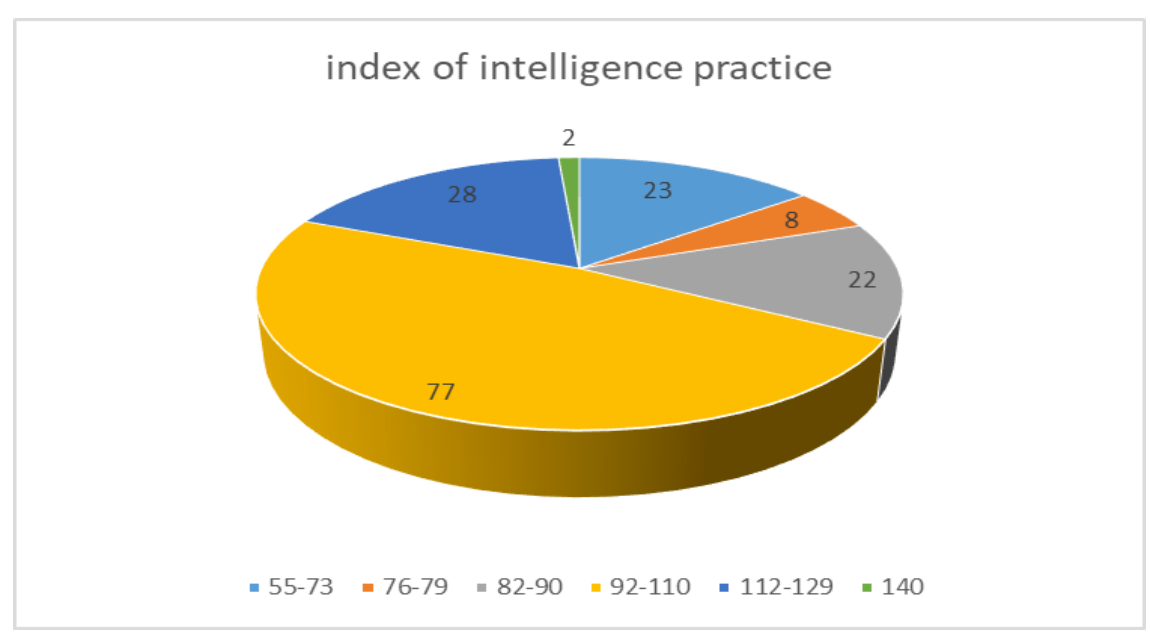

Fig. 4. Graph 4 Frequencies of pupils index of practice intelligence 
In Graph 5, the general index of intelligence has been described. A large proportion of pupils (71 students) have a general intelligence index of 91 to 110 , which corresponds to the average general population index of the general population. A fairly large proportion exceeds the average (35 pupils with an 11-120 intelligence index and 11 students with an IQ of 112-130). A small part (17 students) presents a mental disability, 1 student appears with marginal intelligence, 23 pupils a little below average and a very small part ( 2 pupils) appears to have extraordinary intelligence.

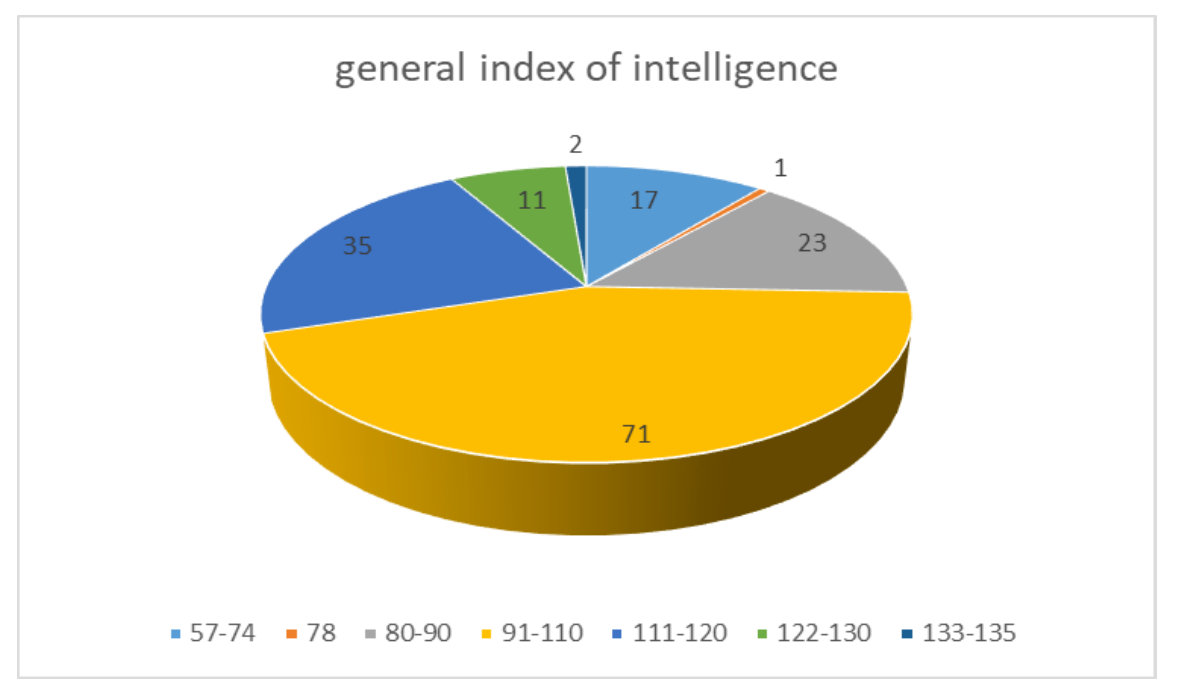

Fig. 5. Graph.5. Frequencies of pupils general index of intelligence

\subsection{Correlations between the variables}

The value of the Pearson Correlation Coefficient between the variable 'performance in the language lesson' and the variables: "index of verbal intelligence" were statistically significant $(\mathrm{r}=0,565, \mathrm{p}=0,000)$, "index of intelligence practice" were statistically significant $(\mathrm{r}=0,347, \mathrm{p}=0,000)$, "general index of intelligence" were statistically significant $(\mathrm{r}=0,488, \mathrm{p}=0,000)$. The value of the Pearson Correlation Coefficient between the variable 'performance in the math lesson' and the variables: "index of verbal intelligence" were statistically significant $(r=0,476, p=0,000)$, "index of intelligence practice" were statistically significant $(r=0,483, p=0,000)$, "general index of intelligence" were statistically significant $(\mathrm{r}=0,528, \mathrm{p}=0,000)$. The value of the Pearson Correlation Coefficient between the variable 'performance in the language lesson' and the variable 'performance in the math lesson' were statistically significant $(r=0,676, p=0,000)$. The value of the Pearson Correlation Coefficient between the variable 'index of verbal intelligence' and the variables: 'index of intelligence practice' were statistically significant $(r=0,655, p=0,000)$, 'general index of intelligence" were statistically significant $(\mathrm{r}=0,885, \mathrm{p}=0,000)$. The value of the Pearson Correlation Coefficient between the variable 'index of intelligence practice' and the variable 'general index of intelligence" were statistically significant $(r=0,923, p=0,000)$. The 
high values of the correlation index indicate that there is a close relationship between the three intelligence indicators that emerged from the wisc-iv test for students and the students' performance in the language lesson and the mathematics lesson.

\section{Conclusions}

The international bibliography defined intelligence as "The ability to solve problems that one encounters in real life; the ability to generate new problems to solve and the ability to make something or offer a service that is valued within one's culture" [40]. Tests, which yielded an individual's intelligence quotient, or IQ, at the dawn of the last century, may provide us the general cognitive profile and consequently the learning path [41]. Intellectual strengths (e.g., long-term memory, ability to think abstractly) and nonintellectual strengths (e.g., motivation, self-discipline) surely both contribute to a student's academic performance. Valid measures of IQ have been available since the early 1900 s, making possible serious research into the correlates and consequences of intellectual ability and school performance [42]. Since early childhood is popularly regarded as efforts to evaluate children's achievements and IQ is the best available predictor of school performance and is a particularly compelling rationale for its use as an assessment criterion [43].

The study aimed to investigate the associations between different IQ index and levels, with different aspects of school performance. The main finding showed that high school performance in language and math, associate significantly with high IQ level in "general index of intelligence", when studied simultaneously in a multivariate analysis. In line with the majority of previous studies we found that high performance in language and math is associated with high IQ level in "general index of intelligence and excellent academic achievement"[44], [45], [46], [47], [48], [49]. [50], [51], [52]. Cognitive ability is a well-established predictor of academic achievement and in particular language is the main pillar of the conception [53]. In addition the high cognitive processes of high school lessons require high levels of language development.

Perhaps of most interest, in our research is the interaction between performance in the language lesson and performance in the math lesson, which were statistically significant. The nature of the interaction between mathematical, verbal, and general intellectual abilities with achievement in mathematics has long been a primary research concern of mathematics educators. It is generally recognized that not only do linguistic abilities affect performance in mathematics but also that mathematics itself is a specialized language [54], [55], [56] [57]. A primary goal of instruction for schools is the development of students with mathematics skills. Mathematics is defined as a language that is used to express relations between and among objects, events, and times. The language of mathematics employs a set of symbols and rules to express these relations [58]. [59]. Word problems constitute one of the most important mediums through which students can potentially learn to select and apply strategies necessary for coping with everyday problems. To comprehend and solve mathematical word, or story, problems, one must be able to keep track of incoming information. 
This is necessary to understand words, phrases, sentences, and propositions that, in turn, are necessary to construct a coherent and meaningful interpretation of word problems [60].

Due to the cross-sectional design of this study it remains unknown whether the adolescents' school performance was impaired due to low IQ or whether negative life events or learning disabilities contributed to their low performance. There are many potential risk factors and diverse pathways to low performance in language and math. However, cognitive aspects seem to be of major importance in adolescent academic achievements. From a theoretical point of view, an adolescent's conceptualization of decline in academic performance as a consequence of personal deficiencies seems to contribute to low performance via self-esteem and negative attributions. Future studies should focus in more detail on associations between aspects of school performance and different levels of IQ, in order to find entries for intervention for students with low performance.

\section{$7 \quad$ References}

[1] Melhuis.k\& Falloon G.(2010).Looking to the future:-M-Learning with the I-pad., 1-16

[2] Litchfield, A. J., Dyson, L. E., Lawrence, E. M., \& Bachfischer, A. (2007). Directions for mlearning research to enhance active learning. In Annual Conference of the Australasian Society for Computers in Learning in Tertiary Education. Centre for Educational Development, Nanyang Technological University.

[3] Chu, H. C., Hwang, G. J., Tsai, C. C., \& Tseng, J. C. (2010). A two-tier test approach to developing location-aware mobile learning systems for natural science courses. Computers \& Education, 55(4), 1618-1627 https://doi.org/10.1016/j.compedu.2010.07.004

[4] Murray, O. T., \& Olcese, N. R. (2011). Teaching and learning with iPads, ready or not?. TechTrends, 55(6), 42-48. https://doi.org/10.1007/s11528-011-0540-6

[5] Schuck, S. R., Aubusson, P. J., Kearney, M. D., \& Burden, K. (2010). Mobagogy-Mobile learning for a higher education community. In International Association for Development of the Information Society International Conference. International Association for Development of the Information Society (IADIS)

[6] Perkins, C., Johnson, D., \& Arkko, J. (2011). Mobility support in IPv6 (No. RFC 6275)

[7] Mirenda, P. (2003). "He's not really a reader...": Perspectives on supporting literacy development in individuals with autism. Topics in Language Disorders, 23(4), 271-282 https://doi.org/10.1097/00011363-200310000-00003

[8] Chung, L., \& do Prado Leite, J. C. S. (2009). On non-functional requirements in software engineering. In Conceptual modeling: Foundations and applications (pp. 363-379). Springer, Berlin, Heidelberg https://doi.org/10.1007/978-3-642-02463-4 19

[9] Goldsmith, T. R., \& LeBlanc, L. A. (2004). Use of technology in interventions for children with autism. Journal of Early and Intensive Behavior Intervention, 1(2), 166 https://doi.org/10.1037/h0100287

[10] Upadhyay, N. (2006). M-Learning- a new paradigm in education. International Journal of Instructional Technology and Distance Learning, 3(2), 31-34.

[11] Chung, L., \& do Prado Leite, J. (2009). Non-functional requirements in software engineering. Conceptual modelling: foundations and applications. In A. T. Borgida, et al. (Eds.).Mylopoulos Festschrift, Lecture notes in computer science, Vol. 5600 (pp. 363379). Berlin Heidelberg: Springer-Verlag. 
Paper-Mobile Application Tools for Students in Secondary Education. An Evaluation Study.

[12] Franklin, T., \& Peng, L. W. (2008). Mobile math: Math educators and students engage in mobile learning. Journal of Computing in Higher Education, 20(2), 69-80 https://doi.org/10.1007/s12528-008-9005-0

[13] Kiger, D., Herro, D., \& Prunty, D. (2012). Examining the influence of a mobile learning intervention on third grade math achievement. Journal of Research on Technology in Education, 45(1), 61-82. https://doi.org/10.1080/15391523.2012.10782597

[14] Hwang, G. J., \& Chang, H. F. (2011). A formative assessment-based mobile learning approach to improving the learning attitudes and achievements of students. Computers \& Education, 56(4), 1023-1031. https://doi.org/10.1016/j.compedu.2010.12.002

[15] Huizenga, J., Admiraal, W., Akkerman, S., \& Dam, G. T. (2009). Mobile game-based learning in secondary education: engagement, motivation and learning in a mobile city game. Journal of Computer Assisted Learning, 25(4), 332-344 https://doi.org/10.1111/j.1365-2729.2009.00316.x

[16] Fehske, A., Fettweis, G., Malmodin, J., \& Biczok, G. (2011). The global footprint of mobile communications: The ecological and economic perspective. IEEE Communications Magazine, 49(8) https://doi.org/10.1109/MCOM.2011.5978416

[17] Stav, J., Nielsen, K., Hansen-Nygard, G., \& Thorseth, T. (2010). Experiences obtained with integration of student response systems for iPod Touch and iPhone into e-learning environments. Electronic Journal of e-learning, 8(2), 179-190

[18] Cheong, C., Bruno, V., \& Cheong, F. (2012). Designing a mobile-app-based collaborative learning system. Journal of Information Technology Education: Innovations in Practice, 11(1), 94-119 https://doi.org/10.28945/1582

[19] Vázquez-Cano, E. (2014). Mobile distance learning with smartphones and apps in higher education. Educational Sciences: Theory and Practice, 14(4), 1505-1520 https://doi.org/10.12738/estp.2014.4.2012

[20] Vasiliou, A., \& Economides, A. A. (2007). Mobile collaborative learning using multicast MANETs. International Journal of Mobile Communications, 5(4), 423-444 https://doi.org/10.1504/IJMC.2007.012789

[21] Vantroys, T., \& Peter, Y. (2003). COW, a flexible platform for the enactment of learning scenarios. Groupware: Design, Implementation, and Use, 168-182 https://doi.org/10.1007/978-3-540-39850-9 15

[22] Livesay, P. A. (2015). Investigation of capabilities and technologies supporting rapid UAV launch system development. NAVAL POSTGRADUATE SCHOOL MONTEREY CA

[23] Chuang, Y. T. (2015). SSCLS: A smartphone-supported collaborative learning system. Telematics and Informatics, 32(3), 463-474 https://doi.org/10.1016/j.tele.2014.10.004

[24] Cripps, I.,B.,McHenry,R(2017) The Future of Psychometric Testing. Published Online: 18 MAR 2017 (pp 269). https://doi.org/10.1002/9781119183020

[25] Contreras, A., R., Salcedo, L.,P., Pinninghoff,J.,M., A., (2009) Performance of High School Students in Learning Math: A Neural Network Approach, in proceedings International Work-Conference on the Interplay Between Natural and Artificial Computation (IWINAC) 2009: Bioinspired Applications in Artificial and Natural Computation (pp 519-527).

[26] Bekele, R.,Menzel,W.,(2005) "A Bayesian approach to predict performance of a student (BAPPS): A case with Ethiopian students," in proceedings of the International Conference on Artificial Intelligence and Applications (AIA-2005), Vienna, Austria from www.informatik.uni-hamburg.de

[27] Pilgrim, J., Bledsoe, C.,Riley, S. (2012) New technologies in the classroom. The Delta Kappa Gamma Bulletin, 78(4), pp 16-22. 
Paper-Mobile Application Tools for Students in Secondary Education. An Evaluation Study.

[28] McMahon, D.D.,Cihak, D.F.,Gibbons, M.M.,Fussell,L.,Mathison,S.(2013) Using a Mobile App to Teach Individuals with Intellectual Disabilities to Identify Potential Food Allergens, Journal of Special Education Technology, Volume 28, Number 3,pp 21-33. https://doi.org/10.1177/016264341302800302

[29] Fergus,P., Abdulaimma,B.,Carter, C.,Round,S. (2014) Interactive mobile technology for children with autism spectrum condition (ASC) in proceedings conference Consumer Communications and Networking Conference (CCNC),11th, LasVegas, NV,USA, from ieeexplore.ieee.org

[30] Ahmad,W.F.,W., Muddin, H.N.B.,I.,Shafie,A. (2014) Number skills mobile application for Down Syndrome children in proceedings conference de International Conference on Computer and Information Sciences (ICCOINS), 2014 from ieeexplore.ieee.org.

[31] Mechling, L. C., \& Savidge, E. J. (2011). Using a personal digital assistant to increase completion of novel tasks and independent transitioning by students with autism spectrum disorder. Journal of autism and developmental disorders, 41(6), 687-704 https://doi.org/10.1007/s10803-010-1088-6

[32] Gentry, T., Wallace, J., Kvarfordt, C., \& Lynch, K. B. (2010). Personal digital assistants as cognitive aids for high school students with autism: Results of a community-based trial. Journal of Vocational Rehabilitation, 32(2), 101-107

[33] Carmien, S., Kollar, I., Fischer, G., \& Fischer, F. (2007). The interplay of internal and external scripts. Scripting computer-supported collaborative learning, 303-326 https://doi.org/10.1007/978-0-387-36949-5 17

[34] Fogg, B. J., Soohoo, C., Danielson, D. R., Marable, L., Stanford, J., \& Tauber, E. R. (2003, June). How do users evaluate the credibility of Web sites?: a study with over 2,500 participants. In Proceedings of the 2003 conference on Designing for user experiences (pp. 1-15). ACM https://doi.org/10.1145/997078.997097

[35] Choi,W., Stvilia, B.(2014) How do college students choose mobile health/wellness applications? Proceedings of the Association for Information Science and Technology, Volume 51, Issue 1Pages 1-4.

[36] Shankar,R.,McAfee,F.X.,Scarlatelli,S.,(2017) A Pipeline of High Achievers to STEM Program, American Society for Engineering Education, paper ID 19961

[37] Ventola, C. L.(2014) Mobile Devices and Apps for Health Care Professionals: Uses and Benefits. Pharmacy and Therapeutics,39(5): pp 356-364.

[38] Murfin, M. (2013) Know your apps: an evidence-based approach to the evaluation of mobile clinical applications. The Journal of Physician Assistant Education, 24(3): pp 38-40 https://doi.org/10.1097/01367895-201324030-00008

[39] O’Neill K.,M., Holmer, H.,Greenberg,S.,L.,Meara, J.,G.(2013) Applying surgical apps: Smartphone and tablet apps prove useful in clinical practice. Bulletin of the American College of Surgeons, 98(11): pp10-18

[40] Christensen, C. M. (2011). Disrupting Class: How Disruptive Innovation Will Change the Way the World Learns. New York: McGraw Hill.(pp. 25-26) .

[41] Kivunja,CH.(2015)Creative engagement of digital learners with gardner's bodilykinesthetic intelligence to enhance their critical thinking.Creative Education, 6, pp 612-622 https://doi.org/10.4236/ce.2015.66060

[42] Duckworth, A. S., Seligman, M. E. P. (2005) Selfdiscipline outdoes IQ in predicting academic performance of adolescents. Psychological Science, 16, pp 939-944 https://doi.org/10.1111/j.1467-9280.2005.01641.x

[43] Aylward GP.( 2002) Cognitive and neuropsychological outcomes: more than IQ scores. Mental Retardation and Developmental Disabilities Research Reviews,, 8:pp 234-40 https://doi.org/10.1002/mrdd.10043 
Paper-Mobile Application Tools for Students in Secondary Education. An Evaluation Study.

[44] Blair, C. (2002). School readiness: Integrating cognition and emotion in a neurobiological conceptualization of children's functioning at school entry. American Psychologist, 57, 111-127 https://doi.org/10.1037/0003-066X.57.2.111

[45] Christian, K., Bachman, H. J., Morrison, F. J. (2001). Schooling and cognitive development. In R. J. Sternberg \& R. L. Grigorenko (Eds.), Environmental effects on cognitive abilities (pp. 287-335). Mahwah, NJ: Lawrence Erlbaum.

[46] Gutman, L. M., Sameroff, A. J., Cole, R. (2003). Academic growth curve trajectories from 1st grade to 12th grade: Effects of multiple social risk factors and preschool child factors. Developmental Psychology, 39,pp 777-790. https://doi.org/10.1037/0012-1649.39.4.777

[47] Henry,L. A.,MacLean,M.(2003). Relationships between working memory, expressive vocabulary and arithmetical reasoning in children with and without intellectual disabilities. Educational and Child Psychology, 20, pp 51-64

[48] Gerber,M.,Durgunoglu,A.Y.(2004).Reading risk and intervention for young English learners: Evidence from longitudinal intervention research .Introduction to special series. Learning Disabilities Research \& Practic, vol. 19, pp 199 -201. https://doi.org/10.1111/j.1 540-5826.2004.00105.x

[49] Bratko, D., Chamorro-Premuzic,T.,Saks, Z. (2006). Personality and school performance: Incremental validity of self- and peer-ratings over intelligence. Personality and Individual Differences, 41, pp 131-142. https://doi.org/10.1016/j.paid.2005.12.015

[50] Chamorro-Premuzic,T.,Arteche, A. (2008). Intellectual competence and academic performance. Intelligence, 36, pp 564-573. https://doi.org/10.1016/j.intell.2008.01.001

[51] Lemos, G. C., Abad, F. J., Almeida, L. S., Colom, R. (2013). Sex differences on g and non-g intellectual performance reveal potential sources of STEM discrepancies. Intelligence, 41(1), pp 11-18. https://doi.org/10.1016/j.intell.2012.10.009

[52] Lemos, G. C., Abad, F. J., Almeida, L. S., Colom, R. (2014). Past and future academic experiences are related with present scholastic achievement when intelligence is controlled. Learning and Individual Differences, 32, pp 148-155. https://doi.org/10.1016/j.lindif. 2014.01.004

[53] Mark,D.,Kern,L.(2014)Increasing Induction-Level Teachers' Positive-to- Negative Communication Ratio and Use of Behavior-Specific Praise Through Emailed Performance Feedback and Its Effect on Students' Task Engagement Journal of Positive Behavior Interventions 16:pp 219-233. https://doi.org/10.1177/1098300713492856

[54] Rollnick,M., Rutherford, M. (1996)The use of mother tongue and English in the learningand expression of science concepts: A classroom-based study. International Journal of Science Education 18 (1), pp 91-103. https://doi.org/10.1080/0950069960180108

[55] Moschkovich, J. (1999)Supporting the participationof English language learners in mathematical discussions. For the Learning of Mathematics 19 (1), 11-19.

[56] de Villiers, J. G. (2005). Can language acquisition give children a point of view? In J. W. Astington \& J. A. Baird (Eds.), Why language matters for theory of mind (pp. 186 - 219). New York: Oxford University Press https://doi.org/10.1093/acprof:oso/9780 195159912.003 .0010

[57] Shanahan, T., Shanahan, C. (2008). Teaching disciplinary literacy to adolescents: Rethinking content-area literacy. Harvard Educational Review, 78(1), pp 40-59. https://doi.org/10.17763/haer.78.1.v62444321p602101

[58] Jordan, N., Kaplan, D.,Hanich, L. (2002). Achievement growth in children with learning difficulties in mathematics: Findings of a two-year longitudinal study. Journal of Educational Psychology, 94, pp 586-597 https://doi.org/10.1037/0022-0663.94.3.586 
[59] Clarke, B., Shinn, M. (2004). A preliminary investigation into the identification and development of early mathematics curriculum-based measurement. School Psychology Review,pp 33, 234-248

[60] Swanson, H. L., Beebe-Frankenberger, M. E. (2004). The relationship between working memory and mathematical problem solving in children at risk and not at risk for serious math difficulties. Journal of Educational Psychology, 96, pp471-491. https://doi.org/10.1037/0022-0663.96.3.471

\section{Authors}

Zoe Karabatzaki is a School Advisor at the 21st Preschool Educational Region of Athens. She holds a Ph.D. on Educational Sciences (Special Education). She has participated in many educational seminars and conferences as a keynote speaker and as instructor. Furthermore, she has taken part in research programs that were supported by many universities of Greece. She has written two books, chapters in collective volumes, articles in scientific journals and educational notes. She has taught at the Department of Special Education of UTH (University of Thessaly), at the Department of Education and Early Childhood of UOA and the Department of Greek Literary of Democritus University of Thrace. She is also a scientific associate at Net Media Lab of N.C.S.R. 'Demokritos'. (e-mail:zkarabatzaki@gmail.com\}

Agathi Stathopoulou is a teacher in Secondary Education with a specialization in Greek philology. She holds a $\mathrm{PhD}$ in Special Education. She has taken part in research projects and seminars. At the current period is serving as a special educator at the Center for Diagnosis, Differentiation and Support, where pupils with special educational needs are assessed, in the B area of Athens. She is also a scientific associate at Net Media Lab of N.C.S.R. 'Demokritos'. (agathi.stathopoulou@yahoo.com)

Georgia Kokkalia (MSc in Specific Learning Difficulties) is a Special Education Teaching Professional and Phd Candidate in University of Athens. She has participated in various research projects regarding the use of Information and Communication Technologies (ICTs) in Special Education and in Kindergarten (gioulina@hotmail.com).

Eleni Dimitriou (MSc in Special Needs and Inclusive Education) is a Special Education Teaching Professional in Secondary Education and a Phd Candidate, for the University of Athens. She is also a scientific associate at Net Media Lab of N.C.S.R. 'Demokritos'. She has participated in various research projects in Special Education and as Rapporteur for the Seminar: "Special Education subjects with the support of the Technology" (lena.dimitriou@yahoo.gr).

Paraskevi Ioanna Loukeri (Msc Education Management and Leadership in the University of Southampton), is a Primary School Teacher and $\mathrm{PhD}$ candidate in the Kapodistrian University of Athens. She has publications on educational management and she is also a scientific associate at Net Media Lab of N.C.S.R. 'Demokritos'. (vivianlouke@gmail.com).

Alexandra Economou is an assistant professor at the University of Athens in the department of Psychology. She teaches undergraduate and postgraduate neuropsychology and experimental psychology courses at the University of Athens in the De- 
partment of Psychology while her interests focus on cognitive and biological psychology. Dr. Economou is also vice-president of the Greek Aphasia Association. (aoikono@psych.uoa.gr)

Athanasios Drigas is a director of research at N.C.S.R. Demokritos. He is the Coordinator of Telecoms Lab and founder of Net Media Lab since 1996. From 1985 to 1999 he was the Operational manager of the Greek Academic network. He has been the Coordinator of Several International Projects, in the fields of ICTs, and e-services (e-learning, e-psychology, e-government, e-inclusion, e-culture etc). He has published more than 200 articles, 7 books, 25 educational CD-ROMs and several patents. He has been a member of several International committees for the design and coordination of Network and ICT activities and of international conferences and journals. (dr@iit.demokritos.gr).

Article submitted 22 December 2017. Final acceptance 23 January 2018. Final version published as submitted by the authors. 